ARCHÄOLOGISCHE BIBLIOGRAPHIE 1989 



\title{
ARCHÄOLOGISCHE BIBLIOGRAPHIE 1989
}

\author{
VON \\ WERNER HERMANN \\ UND \\ RICHARD NEUDECKER
}

WALTER DE GRUYTER \& CO - BERLIN 1990 
Verlag: Walter de Gruyter \&c Co., Berlin 30

Printed in Germany

Ohne ausdrückliche Genehmigung des Instituts ist es auch nicht gestattet, dieses Buch oder Teile daraus auf photomechanischem Wege (Photokopie, Mikrokopie) zu vervielfältigen

Datenverarbeitung und Satz:

Satz-Rechen-Zentrum Hartmann + Heenemann KG, Berlin

Druck: H. Heenemann GmbH \& Co, Berlin

Buchbinderische Verarbeitung: Lüderitz \& Bauer GmbH, Berlin 